\title{
Urban Women in the Informal Sector: Challenges and Opportunities in Case of Dera Town Oromia Regional State, Ethiopia
}

\author{
Meti Tefera Welkeba ${ }^{* 1}$ Teshome Kessa Degu (Msc) ${ }^{2}$ Sinbone Tefera Walkaba (Msc) ${ }^{3}$ \\ 1.Students in Department of sociology and social work, Addis Ababa, P. O. Box 15732 A.A Ethiopia \\ 2. Oromia Agricultural Research Institute (OARI), Holeta Bee Research Center P. O. Box 22, \\ Holeta, Ethiopia \\ 3. Oromia Agricultural Research Institute (OARI), Holeta Bee Research Center P. O. Box 22, Holeta, Ethiopia
}

\begin{abstract}
Informal sector plays an important role in the provision of means of survival and creation of employment opportunities for the vast majority of poor households around the world. Despite its crucial role, operators face various challenges in the sector. Therefore, the main objective of this study was to investigate urban women in the informal sector; challenges and opportunities in Dera town. Data on the respondent characteristics, motives, challenges, coping mechanisms and possible opportunities were collected through using semi-structured interview from purposively selected sample of 70 women. Both quantitative and qualitative data were employed. Quantitative data was analyzed through descriptive statistics (frequency, means and standard deviation), Qualitative data themes also analyzed through narration analysis with interpretation. Result indicated that there are many factors that respondents raised as reasons for their engagement in tela and ketikela preparation and selling including shortage of land, disagreement, divorce and low education and like. The study also revealed socioeconomic challenges including increased market price of inputs, Lack of access to credit, Seasonal change in demand of LDS, Lack of enough working place and so on. Moreover, coping strategies were identified that helped to reduce adverse effects of those challenges. In addition, the study also explored seven major opportunities among which social capital accounts $24.29 \%$ in its first rank. The study concluded that findings of the study have proved that the access to different types of capitals determine women to take on any income generating activities.
\end{abstract}

Keywords: challenges; informal sector; opportunities; women

DOI: $10.7176 / \mathrm{JMCR} / 85-01$

Publication date: February $28^{\text {th }} 2022$

\section{INTRODUCTION}

The informal sector performing a quintessential position in the human beings in a hardest circumstance to live to tell the tale by means of making employment possibilities for the considerable majority of households round the world (Blades, 2011).

The sector is regard as a major reproduction ground for formal sector employment in which more than half of economically active people in Africa and Asia (Chambwera et al., 2011).

Empirical evidence (Blaauw, 2011 as cited in Gunther, 2012) shows that each guys and female are discovered to be engaged in the casual region globally; however ladies characterize the world's greatest share of employment in the region. In the same report by Gunther (2012), women's participation in Africa money owed $78 \%$ in non-agricultural employment such involvement in day by day wage labor and avenue vending, $61 \%$ in city employment like home work and $93 \%$ in personal job introduction such as being an entrepreneur.

By implication, informal sector is generally a large source of women's employment than for men in many developing countries. For example, the sector in Ethiopia plays a vital role not only by generating income and employment for the poor people but also by producing essential goods and services for many households (Ebisa, 2012).

According to a study by Sebsibe (2015), large numbers of women in Ethiopia are involved in the informal sector. In this regard, the same author indicated that $61 \%$ of working women are engaged in various informal sector income generating activities. From the various informal sector activities, women are predominantly engaged in small retail trading activities, street vending, which involves selling of food and non-food items and production and selling of local drinks such as teji, tella, and areke Individuals are engaged in the informal sector employment because of various reasons. For instance, some join in the sector when they are unable to get job in the formal sector because of low educational level and skills. Meanwhile, others take part for the purpose of supplementing earnings; to diversify their income and some others pro spirit for autonomy (Jopy, 2012).

Despite the fact that informal sector creates employment opportunities for those who are without any alternatives, operators face various challenges in the sector. Feasibly, insufficient or inadequate market information and poor infrastructure are among the major predicament that informal sector operator face 
(Chambwera et al., 2011; Lamba, 2011). While some of these challenges are expected, others are unexpected, occurred accidentally, depending on situations.

As it is the case, humans working in the casual area undertake special coping mechanisms to suffer in their commercial enterprise. It is clearly stated in the works of Arif and Satheesh (2006) that households undertake one-of-a-kind coping mechanisms relying on the kind of issues they have been facing. These techniques encompass moving to much less favored meals with decrease money cost, and reallocating family labor to expand existing income.

Hence, the reasons for women involvement in the informal sector, their challenges and the type of coping mechanism adopted by individuals are different from place to place. Therefore, this study was conducted to investigate urban women in the informal sector; opportunities and challenges in the case of Dera town, Oromia region.

\subsection{Objectives of the Study}

The major objective of this study is to investigate urban women in the informal sector; challenges and opportunities in Dera town, Oromia Regional State.

The specific objectives of the study are:

1. To investigate socio-economic challenges of women in the urban informal sector in Dera town.

2. To examine opportunities of women in the urban informal sector in Dera town.

\section{RESEARCH METHODOLOGY}

\subsection{Description of the Study Area}

The study was conducted in Dera Town, which is found in Arsi Zone of Oromia Regional State and located at $125 \mathrm{~km}$ from capital city of Ethiopia, Addis Ababa at Southeast part and $50 \mathrm{~km}$ from Assela, zonal town to the north. Geographically, the town located at a latitude $08^{\circ} 20^{\prime} \mathrm{N}$ and $39^{\circ} 19^{\prime} \mathrm{E}$ longitude. It is the administrative center of Dodota and Sire Woreda. The area has an estimated total population of 16,731, of which 8,367 are men and 8,364 are women (CSA, 2005). The town has an estimated area of 1550 square kilometers.

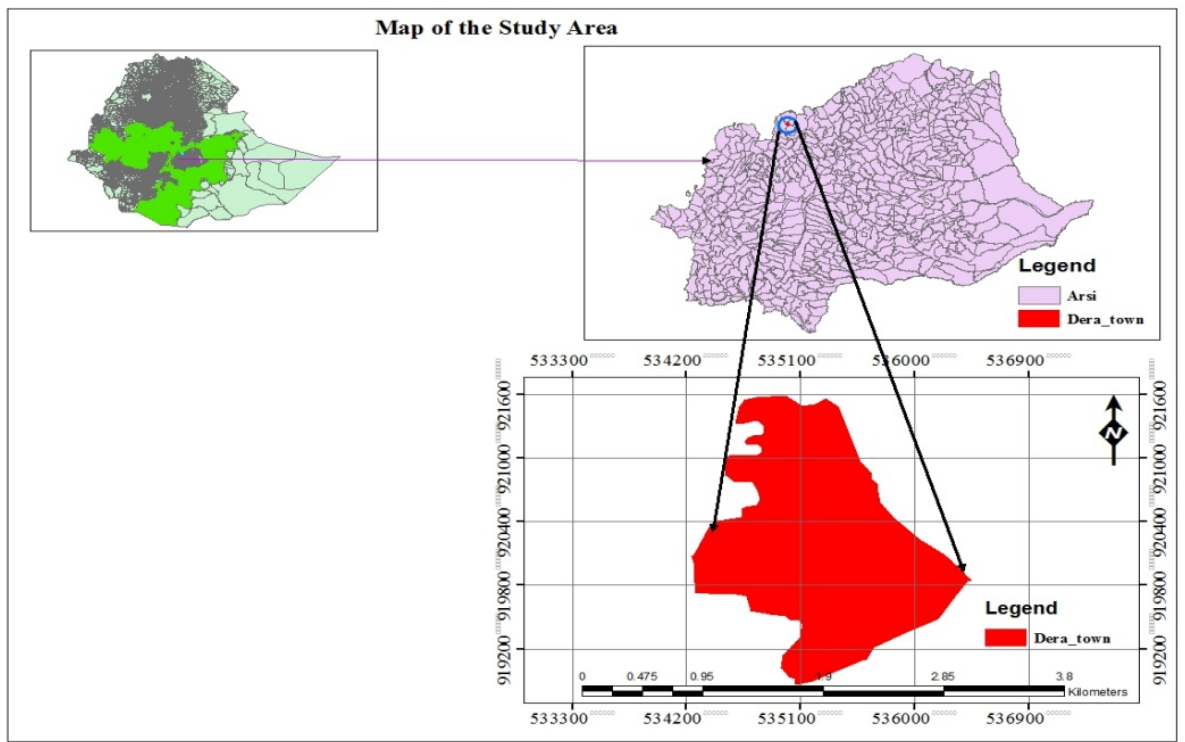

Figure1. Map of the Study Area, Arc GIS software version 10.3, 2021

\subsection{Data Type, Sources and Methods of Data Collection}

The study used both primary and secondary sources of data. The primary data source was data were collected from 70 women's purposively selected, (tela and ketikala) producers and seller, including speeches and oral stories and guiding question (semi-structured) was used to generate data through group discussion and key informant interview with personal observation to support the data obtained from the producer and seller. Whereas, secondary data sources including journal books and articles, and government publication to gather relevant information were used to address the objectives of the study. These data collection was done by the principal researcher.

\subsection{Sampling technique and Sample Size Determination}

The study was conducted using purposive sampling to select target unit. In this regard, Dera Town was selected purposively based on accessibility and convenience. Then, target unit (Tela and Katikala producers and seller) 
was selected purposively. Purposive sampling is a strategy in which particular settings, person, or events are deliberately selected for the important information they can provide, which cannot be obtained from other sources (Babbie, 2007). The demographic data for the research was obtained from Dera town residents, official of town administration to determine sample size and cross-sectional design was used to measure the outcome by identifying challenges and opportunities of women in producing and seliing of tela and katikala in Dera town, different factors was take in to consideration including research cost, time accessibility and availability of transportation facilities.

Sample size of this study was determined through purposive sampling technique based the nature of women producers in the population and their activities in Dera town. The characteristic of the population is homogeneous in the case women are undertaking similar livelihood strategy in producing Tela and Katikala for their income sources. The sample unit selection was held with the managers of the respective kebeles in Dera Town.

Table 1: Sample size of the study

\begin{tabular}{|l|l|l|c|}
\hline Sample frame & Producer population $(\mathrm{N})$ & Sample $(\mathrm{n})$ & Total sample $=\mathrm{n}_{1}+\mathrm{n}_{2}$ \\
\cline { 1 - 2 } Kebele-01 & $\mathrm{N}_{1}=40$ & $\mathrm{n}_{1}=30$ & \multirow{2}{*}{70} \\
\hline Kebele-02 & $\mathrm{N}_{2}=55$ & $\mathrm{n}_{2}=40$ & \\
\hline
\end{tabular}

Source: Dera Administrative Office, 2018

\subsection{Methods of Data Analysis}

The researcher was analyzed and presented through qualitative and quantitative method of data analysis, in which qualitative data of respondent's opinion and views was analyzed using narration method with interpretation and discussion, whereas quantitative data analysis was conducted through summarizing and categorizing the collected data using excel tool. In addition, quantitative data was analyzed through mean and standard deviation using SPSS software version 21.

\section{RESULTS AND DISCUSSION}

\subsection{Demographic Characteristics of Respondents}

Among a total of 70 sampled women interviewed, about $74.29 \%$ and $4.29 \%$ were follower of orthodox and protestant religion, respectively. The remaining $21.42 \%$ were followers of others (wakefeta and Muslim) (Table 2 ). This result indicated that a larger proportion of the respondents were among the Orthodox religion as compared to protestant and others. Regarding marital status, majority (78.57\%) were married, while $11.43 \%$, $2.86 \%$ and $7.14 \%$ of the respondents were unmarried, divorced and widowed at different percentage, respectively. All women who are engaged in the activity (married, unmarried, widowed and divorced) were included in the study.

In the same table 2 , the result shows that about $52.86 \%$ of the respondents were unemployed while the remaining $47.14 \%$ were employed in to different organization as daily laborer before coming to the business. Regarding educational status, majority (37.14\%) of respondents attended the primary school of 1 up to 4 in grade, which was followed by five up to eight $(22.86 \%)$ of the respondent attended the primary school. Some of respondents also attended secondary $(15.71 \%$ ) and higher education (college and university) is $10 \%$, while the remaining $14.29 \%$ were found at read and writes only (Table 2).

\begin{tabular}{|l|l|l|l|}
\hline Variables & Categories & Frequency & Percentage \\
\hline \multirow{4}{*}{ Religion } & Orthodox & 53 & 74.29 \\
\cline { 2 - 4 } & Protestant & 3 & 4.29 \\
\cline { 2 - 4 } & Others & 13 & 21.42 \\
\hline \multirow{5}{*}{ Marital status } & Unmarred & 8 & 11.43 \\
\cline { 2 - 4 } & Married & 55 & 78.57 \\
\cline { 2 - 4 } & Divorced & 2 & 2.86 \\
\cline { 2 - 4 } & Widowed & 5 & 7.14 \\
\hline Erevious occupation & Employed & 33 & 47.14 \\
\cline { 2 - 4 } & Unemployed & 37 & 52.86 \\
\hline \multirow{5}{*}{ Educational status } & Read \& write & 10 & 14.29 \\
\cline { 2 - 4 } & $1-4$ & 26 & 37.14 \\
\cline { 2 - 4 } & $5-8$ & 16 & 22.86 \\
\cline { 2 - 4 } & $9-12$ & 11 & 15.71 \\
\cline { 2 - 4 } & Higher & 7 & 10.00 \\
\hline
\end{tabular}

Source: Own result, 2021

The result presented in table 3 shows that the mean age of respondents accounts 35.82 years with standard deviation of 9.66. The youngest age category of the respondent was aged 20 years while the oldest was aged 58 
years. In fact, age has an important implication in adapting to social and economic challenges they faced in local drinking sells. This is because an aged group had greater experience than young women related with their livelihood activities. As to the result illustrated in the table 3 below, the maximum years of working experience in LDS of the respondents accounts five years at the mean of 2.96 with the 1.16 standard deviation. The mean of family size of the respondents was about 2.64. This mean family size is normal as it found below the national average family size of 4.7 persons per household (CSA, 2007).

Table 2: Descriptive statistics of continuous variables $(n=70)$

\begin{tabular}{|l|r|r|r|r|}
\hline Variables & \multicolumn{1}{|c|}{ Minimum } & \multicolumn{1}{c|}{ Maximum } & \multicolumn{1}{c|}{ Mean } & \multicolumn{1}{c|}{ Std. Deviation } \\
\hline age & 20.00 & 58.00 & 35.83 & 9.66 \\
\hline family size & .00 & 6.00 & 2.64 & 1.66 \\
\hline working experience & 1.00 & 5.00 & 2.96 & 1.16 \\
\hline
\end{tabular}

Source: own result, 2021

\subsection{Socioeconomic Challenges faced by Women in Local Drink Selling}

Local drink promoting creates a main operated exercise to go in advance their family as predominant potential of earnings producing things to do for most women and extra supply of profits for women in Dera town. Nevertheless, there has been almost nothing activities run without any challenges. These sub-sections aimed at discussing the challenges that distress women's livelihood activities (LDS). It involves the leading social and economic challenges that women in LDS faced. Regarding these challenges, the social and economic aspects to LDSs face are ranked and analyzed based on its degree of intensity. However, in this study, the researcher discovered a complete of six (6) essential socioeconomic challenges inclusive of Increased market charge of inputs, Lack of get right of entry to credit, Seasonal trade in demand of LDS, Lack of adequate working place, Disagreement with customers, Competition with different nearby drink dealers

(Table 4).This finding is in line with the studies (Ethiopia, 2000; CSA, 2003; Amene, 2008). These challenges were ranked below in the table.

Table 3: Rank of socioeconomic challenges

\begin{tabular}{|l|l|l|l|}
\hline Challenges & Freq. & Percentage & Rank \\
\hline Increased market charge of inputs & 25 & 35.71 & $1^{\text {st }}$ \\
\hline Lack of get right of entry to credit & 15 & 21.43 & $2^{\text {nd }}$ \\
\hline Seasonal trade in demand of LDS & 11 & 15.71 & $3^{\text {rd }}$ \\
\hline Lack of adequate working place & 10 & 14.29 & $4^{\text {th }}$ \\
\hline Disagreement with customers & 5 & 7.14 & $5^{\text {th }}$ \\
\hline Competition with different nearby drink dealers & 4 & 5.71 & $6^{\text {th }}$ \\
\hline
\end{tabular}

Source: own result, 2021

\subsection{Opportunities of Women in Urban Informal Sector in the Study Area}

This sub-section reveals the results on women opportunities in accordance with addressing the fourth stated objective of this study. To this end, the study result found that there are a total of seven (7) major opportunities explained by the respondents (Table 5). The study result indicated that existence of social capital (relations) for women in informal sector was considered to be one opportunity in the study area. It holds the first rank with highest percentage (24.29\%) among others based on degree of importance and highest value concern by local entrepreneurs (LDS) in Dera town (Table 5).For example, women LDSs tend to draw on their social networks and group membership to survive from their challenges, in the time of market failure. Respondents revealed that they borrow food items such as grains and money from their relatives, lived in the area. A 38-year-old woman key informant also explained her opinion as follows:

I have been engaged in the coaching and promoting of Tela for at least 10 years. I have sturdy relationship with my relatives, neighbors and different nearby drink dealers such as grain merchants (wholesalers) and retailers. This social relationship helped me with the aid of the time there was once reduced in the demand of the neighborhood drink. At this time, I used to borrow some quantity of cash from my household and sold grain from market and put together the Tela for selling. After that I again lower back the cash I borrowed from my household at once when the drink used to be sold. It was once a appropriate chance in that they wait me till the neighborhood drink demand used to be coming and I have gotten the cash in return. I used to be additionally took deposit from my neighbors for residence lease and to purchase some housing objects for consumption cause and back the cash when I received income from promoting the drink (Tela).

Hence, it was confirmed by the researcher in that a strong social network is a good opportunity for women LDS in the study area. The result also revealed that exemption from formal taxation seen as one of major opportunity that women LDS expected for cost-effective business activity. It accounts $18.57 \%$ of respondents explained their satisfaction from the LDs business. This study is conformed with the findings by Mekonnen 
(2017), who stated that women in informal sector enabled to run their business and they were enjoying as their business are free from formal taxation, hence the temporary nature of the structures and display tools they use. Similarly, a study by Tutik (2014) argued that the informal sector employment and incomes are notoriously difficult to tax.

Some of the respondents $(15.71 \%)$ explained that access to market for inputs helps us to buy drinking materials, crops like sorghum, wheat, maize, etc, and have been enable us to run the business easily (table 5). This may be due to the existence of good accesses to market information, market infrastructure, particularly road and mobile telephone networks, in the study area. In addition, the researcher was observed that there was availability of market for inputs that women could access easily as it found nearest to their working place.

Furthermore, existence of demand for local drinks also one of the major opportunities and rank as the third pillar for LDS. For instance, $12.86 \%$ of the respondents stated that there is high demand in the locality especially for Orthodox Christians religion during the celebration of different ceremonies. In addition, the result from FGD held at 02 kebele stated that LD is paramount important and demanded by local communities during social meeting, Wedding ceremony, children birth days, festivals, funeral ceremony, when solving disputants and so on. The fourth and most important opportunity is availability of micro-finance institution.

Hence, result shows that respondents $(11.43 \%)$ stated that availability of micro-finance institution in the area helped to credit money for the startup of LDS as a business (Table 5). It took the fourth in its level of advantage contributed as major opportunity. The result from FGD held 01 kebele in the area revealed that "Micro-finance in our town is a pillar to our livelihood activities." In addition, access to education and training was also stated by the respondents which enable women LDS to handle their business, change social norms and empower them. According to ILO (2012), women with lower levels of education tend to develop and accumulate their skills through "on-the-job" training over time - either at home, through friends and the community, or informal apprenticeships. A detail explanation was given by KII held with manager of women affairs shows that women who accomplish higher education could have access to employ in different organization which help to diversify their income.

Lastly, presence of social protection is the most important opportunity where the few (7.14\%) of the respondents reflected that social protection service from local government and other NGOs was an opportunity for us that helped to care health of women and enable them to be beneficiaries from their business. This finding is consistent with Tessier et al. (2013), explaining social protection schemes, as well as wider social security systems, as it can contribute to women's economic empowerment and gender equality.

Table 4: Opportunities of women in informal sector (LDs)

\begin{tabular}{|l|l|l|l|}
\hline Opportunities & Freq. & Percent & Rank \\
\hline Presence of social protection & 5 & 7.14 & $6^{\text {th }}$ \\
\hline Access to market for inputs & 11 & 15.71 & $3^{\text {rd }}$ \\
\hline Availability of micro-finance institution & 8 & 11.43 & $5^{\text {th }}$ \\
\hline Existence of demand to LD & 9 & 12.86 & $4^{\text {th }}$ \\
\hline Existence of social capital/relations & 17 & 24.29 & $1^{\text {st }}$ \\
\hline Access to education and skills training & 7 & 10.00 & $7^{\text {th }}$ \\
\hline Exemption from formal taxation & 13 & 18.57 & $2^{\text {nd }}$ \\
\hline Total & 70 & 100.00 & \\
\hline
\end{tabular}

Source: own result, 2021

\section{CONCLUSION AND RECOMMENDATIONS}

The study explored to investigate urban women in the informal sector; challenges and opportunities on Dera town, East Arsi Zone, Oromia Regional State. By this stand, the study was intended to address the following specific objectives: to investigate socio-economic challenges of women in the urban informal sector; and to examine opportunities of women in the urban informal sector in Dera town.

The study has employed both primary and secondary data sources where qualitative and quantitative data types generated for further analysis. The Primary data was collected from sampled respondents of 70 selected through purposive sampling technique. In addition, a key-informant interview was held with a total of eight participants: two women who are members of the women affairs, two kebele managers and four elderly people living in the study area. Direct observation was also undertaken by the researcher while data from all sources were triangulated for data validation. Secondary data was also used through critical review documents for supporting the research findings. Data entry and coding were conducted using SPSS version 21. Quantitative data analysis was conducted using STATA version 13 where data was imported from SPSS to STATA for its simplicity. Qualitative data also analyzed and through narration of ideas, opinion and views of respondents with interpretation.

The finding revealed that women who are working in LDS as means of earning income for livelihood has 
been confronting several social challenges. Hence, the researcher found a total of six (6) essential socioeconomic challenges inclusive of increased market charge of inputs, Lack of get right of entry to credit, Seasonal trade in demand of LDS, Lack of adequate working place, Disagreement with customers, Competition with different nearby drink dealers Majority (35.71\%) of respondents claimed that increased market charge of inputs was the most intensive problem to women LDS. For instance, women complained that ongoing fire wood price incensement was considered to be serious challenge. Most of the informants raised it as the most serious contest in recent time.

In addition, the study result found a total of seven (7) major opportunities explained by the respondents (Table 5). These includes: Existence of social capital/relations, Exemption from formal taxation, Access to market for inputs, Existence of demand to LD, Availability of micro-finance institution, Presence of social protection, and Access to education and skills training. The study result indicated that existence of social capital (relations) for women in informal sector was considered to be one of major opportunity in the study area. It holds the first rank with highest percentage $(24.29 \%)$ among others based on degree of importance and highest value concern by local entrepreneurs (LDS) in the study area.

In general, the findings of the study have proved that the access to different types of capitals determine women to take on any income generating activities. For instance, the lack of access to enough agricultural land (natural capital), lack of enough financial capital were among the pushing factors while high social relation (social capital), infrastructural development (physical capital) and having the skill of brewing (human capital) were among the pulling factors. The study also related the challenges women in local drink selling face with the vulnerability context like shocks and seasonality. Moreover, transforming structures process which is one element of the SLF was related with both the challenges as well as the coping strategies. The study, therefore, more or less related to the findings of the study with the literature and the adopted framework of the study.

\subsection{Recommendations}

Socioeconomic challenges that influence LDS by which women complained for the Increased market charge of inputs, Lack of get right of entry to credit, Seasonal trade in demand of LDS, Lack of adequate working place, Disagreement with customers, Competition with different nearby drink seller. Hence, understanding the influence of challenges would help Dera town Administration Office to design and implement more effective options and intervention programs for women in LDS and there by helps to pave way to improve their livelihood strategies. It was believed that the design and implementation of coping strategies requires adequate knowledge on the challenges imposed by socioeconomic factors. In this regard, this study provides a base and point of departure for similar studies in the future. Therefore, the following recommendations were made in order to benefit local women, who need to intervene with the issue under considerations.

The study recommends that the government through the investment on informal education systems, access to training, and access to credit through group formation, access to land/working place, and creation of self-help employment opportunities in the urban area could be underlined as a policy option in the reduction of the negative impacts of challenges related to informal sector.

A better access to credit allows women to start up LD business that enable them to improve their livelihood in general and income in particular. Therefore, this study also recommended that government development institutions (saving \& credit) should create the financial means through affordable credit schemes to enable women in LDS to accelerate their own business in the long run.

The Town Women Youth and Children Affairs in Dera town should aim to empower vulnerable groups (women in LDS), motivate and promote new coping strategies through need based interventions in collaboration with NGOs in the area.

Finally, it was suggested that future empirical research should be undertaken by practitioners in Dera Town to expand this study to nations wide across regions through predicting other factors that affect informal sector (LDS).

\section{REFERENCES}

Amene Afework (2011). "Urban Informal Sector as a Livelihood Strategy of Women: The Case of Tella and KaticalaProducersandSellersin Deben Town, Amhara Regional State." Unpublished MA Thesis. Addis Ababa University, Ethiopia

Arif, D and Satheesh A. 2006. "Livelihood Shocks and Coping Strategies: An Empirical Study of Bangladesh Households". Working for the American Agricultural Economics Association Annual Meeting, Long Beach, California.

Babbie, E. (2007).Research Methods in Sociology. Australia: Cenagage Learning.

Chambwera, M,MacGregor, J., and Baker, A. (2011).“A primer for Development Countries.”International Institute for Environment and Development, working paper. UK Press. Retrieved November 8, 2015.

CSA (Central Statistical Agency).( 2003). Urban National Informal Sector Survey .Retrieved December 16, 
2015.

CSA (Central Statistical Agency).( 2007)population and housing censes in Ethiopia.

CSA.(Central Statistics Agency). (2005). Survey on livestock, 11(331), Addis Ababa, Ethiopia.

Ebisa Deribie. 2012. "Women in the Informal Sector: Evidence from South Western Ethiopia." International Journal of Peace and Development Studies. Volume 3 (6) : 112-117.

Gunther, I. 2012. "Informal Employment in Developing Countries: Opportunity or Last resort." Journal of Development Economics. 1(97): 88-98.

Jopy, K. (2012)."The informal business sector; a survival strategyfor female urban dwellers in Gaborone, Botswana". Unpublished MA Thesis, Department of GenderStudies.(http://www.ubrisa.ub.bw/bitstream/handle/10311/1370/Batsalelwang.pdf?sequence=1

Lamba, A. 2011.Urban Informal Business in Regional Economy.International Journal of Administrative Science and Organization. Volume 18 (3):252-259.

Retrieved December 16, 2015.

Sebsibe Hadis(2015)."Women in The Informal Sector: Retrospect's And Socioeconomic Response in Dessie Town, Ethiopia: The Case of Parallel Trading".International Journal of Developing Societies,4(2):85-94.

SebsibeHadis(2015)."Women in The Informal Sector: Retrospect's And Socioeconomic Response in Dessie Town, Ethiopia: The Case of Parallel Trading".International Journal of Developing Societies,4(2):85-94.

Tessier, L., Stern Plaza, M., Behrendt, C., Bonnet, F. and St-Pierre Guibault, E. (2013) Social protection floors and gender equality: A brief overview. International Labour Organisation

Tutik R (2014). Informal sector and local government revenue: The contribution of street vendors. Journal administrative public, vol, 11 .

Yohannes. M. (2017). Challenges and opportunities of women participating in informal sector in Ethiopia: A special focus on women street vendors in Arba Minch City, International Journal of Sociology and Anthropology, 9(2): 1-9. 